\title{
Mycoplasma bovis subverts autophagy to promote intracellular replication in bovine mammary epithelial cells cultured in vitro
}

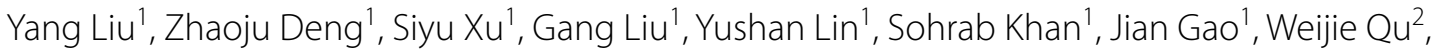
John P. Kastelic ${ }^{3}$ and Bo Han ${ }^{1 *}$ (D)

\begin{abstract}
Mycoplasma species are the smallest prokaryotes capable of self-replication. To investigate Mycoplasma induced autophagy in mammalian cells, Mycoplasma bovis (M. bovis) and bovine mammary epithelial cells (bMEC) were used in an in vitro infection model. Initially, intracellular M. bovis was enclosed within a membrane-like structure in bMEC, as viewed with transmission electron microscopy. In infected bMEC, increased LC3II was verified by Western blotting, RT-PCR and laser confocal microscopy, confirming autophagy at 1, 3 and $6 \mathrm{~h}$ post-infection (hpi), with a peak at 6 hpi. However, the M. bovis-induced autophagy flux was subsequently blocked. P62 degradation in infected bMEC was inhibited at 3, 6, 12 and $24 \mathrm{hpi}$, based on Western blotting and RT-PCR. Beclin 1 expression decreased at 12 and $24 \mathrm{hpi}$. Furthermore, autophagosome maturation was subverted by M. bovis. Autophagosome acidification was inhibited by M. bovis infection, based on detection of mCherry-GFP-LC3 labeled autophagosomes; the decreases in protein levels of Lamp-2a indicate that the lysosomes were impaired by infection. In contrast, activation of autophagy (with rapamycin or HBSS) overcame the $M$. bovis-induced blockade in phagosome maturation by increasing delivery of M. bovis to the lysosome, with a concurrent decrease in intracellular M. bovis replication. In conclusion, although $M$. bovis infection induced autophagy in BMEC, the autophagy flux was subsequently impaired by inhibiting autophagosome maturation. Therefore, we conclude that $M$. bovis subverted autophagy to promote its intracellular replication in bMEC. These findings are the impetus for future studies to further characterize interactions between $\mathrm{M}$. bovis and mammalian host cells.
\end{abstract}

Keywords: Mycoplasma bovis, bovine mammary epithelial cells, autophagy, lysosome, intracellular replication

\section{Introduction}

Mycoplasma species belong to the class Mollicutes and lack a cell wall $[1,2]$. There are several important pathogenic Mycoplasma species with adverse effects on animals and humans [2,3]. These organisms have small genomes and they rely on their hosts for nutrients,

*Correspondence: hanbo@cau.edu.cn

1 Department of Clinical Veterinary Medicine, College of Veterinary Medicine, China Agricultural University, Beijing 100193, China

Full list of author information is available at the end of the article resulting in specialized host-microbe interactions, some of which are not well characterized [4].

Autophagy is a homeostatic and highly conserved survival mechanism in eukaryotic cells to deliver unnecessary cytosolic proteins, organelles, as well as invading pathogens, to lysosomes for degradation [5]. Autophagy can be categorized into 3 main types: microautophagy, macroautophagy and chaperone mediated autophagy. Macroautophagy, which is the best studied, has emerged as an important cellular factor in both innate and adaptive immunity. Xenophagy is often used to describe macroautophagy of microbial original author(s) and the source, provide a link to the Creative Commons licence, and indicate if changes were made. The images or other third party material in this article are included in the article's Creative Commons licence, unless indicated otherwise in a credit line to the material. If material is not included in the article's Creative Commons licence and your intended use is not permitted by statutory regulation or exceeds the permitted use, you will need to obtain permission directly from the copyright holder. To view a copy of this licence, visit http://creativecommons.org/licenses/by/4.0/. The Creative Commons Public Domain Dedication waiver (http://creativeco mmons.org/publicdomain/zero/1.0/) applies to the data made available in this article, unless otherwise stated in a credit line to the data. 
pathogens $[4,6,7]$. After invading host cells, microorganisms are often targeted by autophagy [5], with the protein LC3, diffusely distributed in the cytoplasm, linked to the targeted substrates. The C-terminal fragment of LC3 is cleaved by Atg4 to form LC3-I, activated by Atg7 (an E1-like enzyme), transferred to Atg3 (an E2-like enzyme), and finally modified into a membrane-bound form, LC3II. In general, polyubiquitinated invading pathogens are recognized by the autophagy receptor, P62, that delivers the targeted substrate to LC3II-bound membranes, facilitating autophagosome formation. Beclin1 was disinhibited, serving as a "molecular scaffold" to link autophagosomes to a lysosome when autophagy was initiated. Autophagosome-lysosome fusion represents the next step in degradation, in which hydrolases, e.g., lysosomal-associated membrane protein $2 \mathrm{a}$ (Lamp-2a), are activated by acidification. The final outcome is recycling of cytosolic material or containment of intracellular pathogens [8].

Several studies have verified the crucial role of autophagy in controlling infections by various bacterial pathogens. Furthermore, some of these pathogens have developed strategies to circumvent autophagy or to use it to establish replicative niches within various cell types $[9,10]$. For example, autophagy benefits several bacterial pathogens, including Salmonella and Legionella, although it is an effective defense mechanism inhibiting survival of Mycobacterium tuberculosis in host cells [5, 11, 12]. For Mycoplasma species, which are the smallest prokaryotes capable of self-replication, autophagy has an important role in host-pathogen interactions. For example, Mycoplasma ovipneumoniae induced autophagy in macrophages in vitro [13]. Furthermore, autophagy had a critical role in stimulating the inflammatory response to Mycoplasma pneumoniae infections in mice [14]. However, the fate of M. bovis targeted by autophagy remains uncertain. This bacterium, a hard-to-eradicate ruminant pathogen, causes substantial losses in animal production [3, 15, 16]. Infections with $M$. bovis are usually chronic and difficult to treat [15]. For example, conventional antimicrobial therapy is not very effective for M. bovis mastitis [1, 15, 16]. Furthermore, knowledge gaps in understanding how $M$. bovis persists within mammalian cells contribute to a lack of effective control strategies. Based on previous reports, $M$. bovis can invade into various host cells, including epithelial or immune cells [17-20]. Therefore, we hypothesized that $M$. bovis subverts autophagy to promote its intracellular replication. In the present study, M. bovis and primary bovine mammary epithelial cells (bMEC) were used to establish an in vitro model to characterize autophagy in host cells and resulting implications for survival and replication of intracellular Mycoplasma.

\section{Materials and methods \\ Statement of ethics}

This study was conducted in accordance with the ethical guidelines of China Agricultural University (CAU; Beijing, China). Prior to the beginning of the study, ethical approval was granted by the Departmental Committee of the College of Veterinary Medicine, CAU.

\section{Antibody and reagents}

Enhanced Cell Counting Kit-8 (CCK-8), Ad-mCherryGFP-LC3B, Ad-GFP-LC3B, Bicinchoninic acid (BCA) protein assay kit, Lyso-Tracker red and radioimmunoprecipitation assay (RIPA) lysis buffer (Beyotime Biotechnology) were purchased from Beyotime (Shanghai, China). The PPLO broth was from BD Biosciences (San Jose, CA, USA), whereas horse serum, Fetal Bovine Serum (FBS), Dulbecco modified Eagle medium (DMEM) and Hank balanced salt solution with $\mathrm{Ca}^{2+}$ and $\mathrm{Mg}^{2+}$ (HBSS) were purchased from Hyclone (Logan, UT, USA). Penicillin G, streptomycin, gentamicin, amphotericin and bovine serum albumin (BSA) were from Coolaber (Beijing, China). Collagenase IV, $0.4 \mathrm{mg} / \mathrm{mL}$ DNAse I, $0.5 \mathrm{mg} / \mathrm{mL}$ hyaluronidase I-S, rapamycin and 3-methyladenine were from Sigma-Aldrich (St. Louis, MO, USA). Polyvinylidene difluoride membrane was from Millipore (Bedford, MA, USA). Coverslips, 4', 6-Diamidine-2'-phenylindole dihydrochloride (DAPI) and Triton X-100 were all purchased from Solarbio (Beijing, China). An enhanced chemiluminescence (ECL) kit was obtained from Thermo Fisher Scientific Pierce (Rockford, IL, USA). Anti-p62 antibody and anti-glyceraldehyde 3-phosphate dehydrogenase (GAPDH) antibody were purchased from Abcam (Cambridge, MA, USA). Anti-LAMP2 antibody and anti- $\beta$ actin antibody were obtained from Beyotime. Anti-LC3B antibody, anti-Beclin1 antibody and anti-cytokeratin 18 (CK18) were from Proteintech (Chicago, IL, USA). Peroxidase-conjugated goat anti-mouse IgG were from ZSGB-BIO (Beijing, China). Goat anti-rabbit IgG were from Beyotime. Alexa fluor conjugated antibodies were purchased from Cell Signaling Technology (Danvers, MA, USA) and Freund incomplete adjuvant was from Sigma-Aldrich.

\section{M. bovis strain and growth conditions}

M. bovis strain PG45 (ATCC 25,523) was purchased from the ATCC. For infection experiments, M. bovis were cultured in PPLO broth with $20 \%$ horse serum and penicillin $(100 \mathrm{IU} / \mathrm{L})$ in $5 \% \mathrm{CO}_{2}$ at $37{ }^{\circ} \mathrm{C}$ for $72 \mathrm{~h}$. The PPLO broth was prepared by dissolving $21 \mathrm{~g}$ of Difco PPLO medium (BD Biosciences) and $2.5 \mathrm{~g}$ of yeast extract (BD 
Biosciences) in $700 \mathrm{~mL}$ of ultrapure water, then autoclaving it at $121{ }^{\circ} \mathrm{C}$ for $30 \mathrm{~min}$. M. bovis were collected by centrifugation $(8000 \times g$ for $40 \mathrm{~min})$ and then washed with phosphate-buffered saline (PBS). The number of colony forming units was determined by performing ten-fold serial dilutions in PBS and subsequently spotting on PPLOA plates [18], prepared by supplementing PPLO broth with $20 \%$ horse serum and $0.75 \%$ agar. The bacteria were suspended in PBS to a cell density of $10^{8}$ colony-forming units per milliliter $(\mathrm{CFU} / \mathrm{mL})$, and the suspension was stored at $-70{ }^{\circ} \mathrm{C}$ until use [21].

\section{Mouse anti-M. bovis serum preparation}

BALB/c mice, 6-8 weeks old, were immunized with 1 $\times 10^{6}$ CFU M. bovis strain PG45 mixed with an equal volume of Freund incomplete adjuvant and delivered by multipoint subcutaneous injections. Mice were immunized 3 times at 2-week intervals. At 2 weeks after the last immunization, mice were euthanized and blood was collected and incubated at $37^{\circ} \mathrm{C}$ for $0.5 \mathrm{~h}$, followed by incubation at $4{ }^{\circ} \mathrm{C}$ for $0.5 \mathrm{~h}$. Serum from all mice were combined to form a common pool and stored at $-20^{\circ} \mathrm{C}$.

\section{Cell culture}

Primary bovine mammary gland epithelial cells were collected as described [22, 23] from lactating Holstein cows with clinically healthy udders (milk somatic cell count $<10^{5}$ cells $/ \mathrm{mL}$ ). Briefly, $\sim 100 \mathrm{~g}$ of mammary gland tissue was obtained within $30 \mathrm{~min}$ after slaughter and transported to the laboratory at room temperature $\left(23 \pm 3^{\circ} \mathrm{C}\right)$ in $500 \mathrm{~mL}$ Hank balanced salt solution with $\mathrm{Ca}^{2+}$ and $\mathrm{Mg}^{2+}$ (HBSS) supplemented with $500 \mu \mathrm{L}$ penicillin G $(100 \mathrm{mg} / \mathrm{mL}), 500 \mu \mathrm{L}$ streptomycin $(100 \mathrm{mg} / \mathrm{mL})$, $500 \mu \mathrm{L}$ gentamicin $(100 \mathrm{mg} / \mathrm{mL})$, and $500 \mu \mathrm{L}$ amphotericin $(5 \mathrm{mg} / \mathrm{mL})$.

The following were conducted in a laminar flow hood under sterile conditions. Tissue was washed with HBSS and surface tissue excised and discarded. Interior tissue was minced into $1 \mathrm{~cm}^{3}$ pieces, followed by incubation for $1 \mathrm{~h}$ in $500 \mathrm{~mL}$ HBSS supplemented with $500 \mu \mathrm{L}$ penicillin $\mathrm{G}(100 \mathrm{mg} / \mathrm{mL}), 500 \mu \mathrm{L}$ streptomycin $(100 \mathrm{mg} / \mathrm{mL})$, $500 \mu \mathrm{L}$ gentamicin $(100 \mathrm{mg} / \mathrm{mL})$, and $500 \mu \mathrm{L}$ amphotericin $(5 \mathrm{mg} / \mathrm{mL})$ at $37{ }^{\circ} \mathrm{C}$. Then, tissue blocks were further minced into $1-5 \mathrm{~mm}^{3}$ pieces that were rinsed several times with HBSS to remove milk and blood. These tissue blocks were transposed into $250 \mathrm{~mL}$ HBSS with final concentrations of $0.5 \mathrm{mg} / \mathrm{mL}$ collagenase IV, $0.4 \mathrm{mg} / \mathrm{mL}$ DNAse I, $0.5 \mathrm{mg} / \mathrm{mL}$ hyaluronidase I-S, penicillin $\mathrm{G}(100 \mu \mathrm{g} / \mathrm{mL})$, streptomycin $(100 \mu \mathrm{g} / \mathrm{mL})$, gentamicin $(100 \mu \mathrm{g} / \mathrm{mL})$, and amphotericin $(5 \mu \mathrm{g} / \mathrm{mL})$. Digestion was performed for $3 \mathrm{~h}$ at $37^{\circ} \mathrm{C}$, with the liquid swirled every $10 \mathrm{~min}$. Then, the suspension was filtered through sterile metal strainers (pore size $\sim 1 \mathrm{~mm}^{2}$ ) and the cells were subsequently collected by centrifugation for $10 \mathrm{~min}$ at $1000 \mathrm{~g}$. Pellets were resuspended in $1 / 2 \mathrm{vol}-$ ume HBSS, filtered through sterile metal strainers (pore size $\sim 0.5 \mathrm{~mm}^{2}$ ), and centrifuged for $10 \mathrm{~min}$ at $1000 \mathrm{~g}$. Pellets were re-suspended in $1 / 2$ volume HBSS, filtered through sterile metal strainers (pore size $\sim 70 \mu \mathrm{m}^{2}$ ), and centrifuged for $10 \mathrm{~min}$ at $1000 \mathrm{~g}$. The precipitate was resuspended in $1 \mathrm{~L}$ full medium with $10 \%$ FBS and $1 \mathrm{~mL}$ penicillin $\mathrm{G}(100 \mathrm{mg} / \mathrm{mL}), 1 \mathrm{~mL}$ streptomycin $(100 \mathrm{mg} /$ $\mathrm{mL})$, and $1 \mathrm{~mL}$ amphotericin $(5 \mathrm{mg} / \mathrm{mL})$. Cells were purified by differential adhesion, as follows [22, 23]. Cells were transferred into a $150 \mathrm{~T}$ flask and incubated in 5\% $\mathrm{CO}_{2}$ at $37{ }^{\circ} \mathrm{C}$ for $30 \mathrm{~min}$ to allow fibroblasts to attach. Epithelial cells were decanted and counted after staining by trypan blue. Cells were seeded in $25 \mathrm{~T}$ flasks at a concentration of $1 \times 10^{5}$ cells $/ \mathrm{mL}$ for routine subculture. One passage was defined as one time subculture and purification was done in passages $1-3$. The bMEC in passages $6,7,8$ and 9 were stained with CK18, a marker of luminal epithelial cells $[24,25]$, and identified by fluorescence microscopy. Briefly, bMEC were seeded in 6 well-plates with coverslips. When cells reached $60-70 \%$ confluence, they were fixed in $4 \%$ paraformaldehyde at room temperature for $15 \mathrm{~min}$. Then cells were washed twice in PBS, resuspended in $1 \mathrm{~mL}$ PBS, and incubated with anti-CK18 antibody (at a dilution of 1:200 in PBS) at $4{ }^{\circ} \mathrm{C}$ overnight (14-16 h). Cells were washed twice in PBS and resuspended in $1 \mathrm{~mL}$ PBS, and incubated with Alexa Fluor-conjugated secondary antibodies for $0.5 \mathrm{~h}$ at RT. Thereafter, cells were stained with DAPI and imaged with a Nikon A1 LFOV confocal microscope at laser wavelengths of 405 and $488 \mathrm{~nm}$. The purity of bMEC was defined as the proportion of CK18-positive cells among total cells (stained by DAPI). A random selection of 5 fields per sample was analyzed, with 3 repeats conducted for cells in each passage.

\section{Cell infection and gentamicin protection assay}

The PG45 strain was used to explore intracellular replication of Mycoplasma in bMEC, following a protocol presented in Figure 1A. Viable M. bovis in the inoculum were counted, as described above. Specifically, cells were seeded at a concentration of $1 \times 10^{5}$ cells $/ \mathrm{mL}$ in 6 well plates ( $2 \mathrm{~mL}$ per well) $24 \mathrm{~h}$ prior to experiments. The bMEC were inoculated (time $=0 \mathrm{~h}$ ) with $M$. bovis at multiplicities of infection (MOI) of 1:30 when cells reached $60-70 \%$ confluence. After infection at $37{ }^{\circ} \mathrm{C}$ for $1 \mathrm{~h}$, the inoculum was removed and cells were washed twice with sterilized PBS, $2 \mathrm{~mL} /$ well, to remove nonadherent $M$. bovis. Thereafter, all extracellular M. bovis were killed by the addition of $2 \mathrm{~mL} /$ well DMEM with $400 \mu \mathrm{g} /$ $\mathrm{mL}$ gentamicin for $2 \mathrm{~h}$ at $37^{\circ} \mathrm{C}($ time $=1 \mathrm{~h})$. Cells were again washed as described above. Finally, fresh DMEM 
A

$\begin{array}{ccc}\text { Infection } & \text { GM } & \text { GM } \\ (\mathrm{MOI}=1: 30) & (400 \mu \mathrm{g} / \mathrm{mL}) & (20 \mu \mathrm{g} / \mathrm{mL})\end{array}$
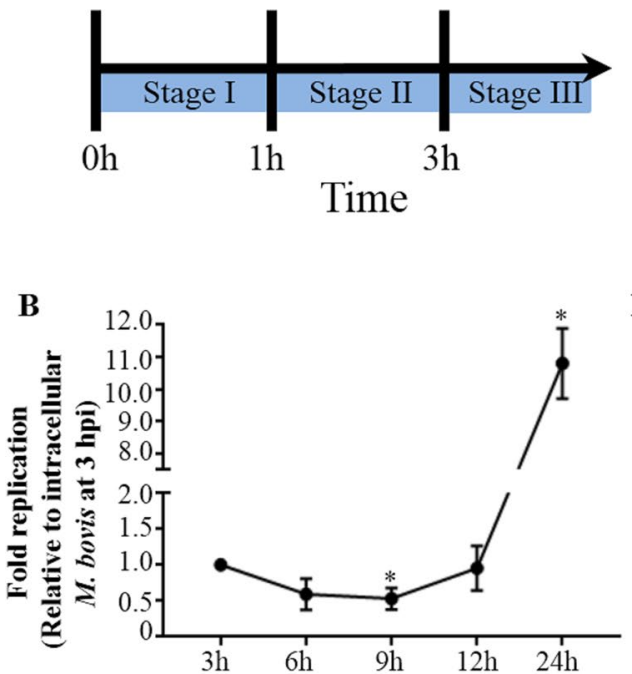

C

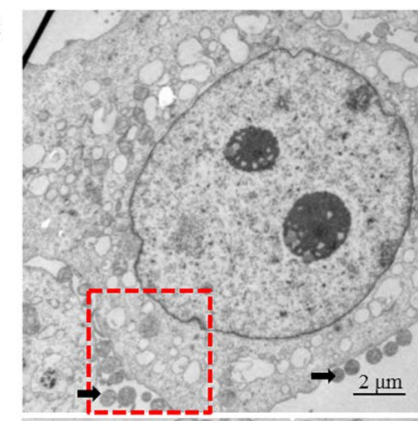

$\mathrm{D}$

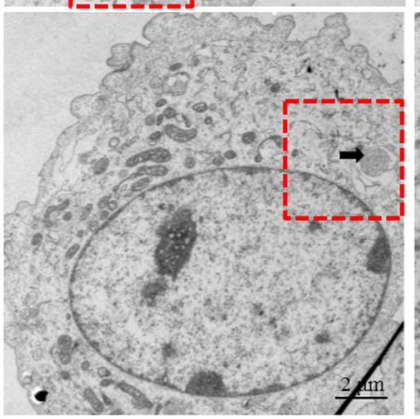

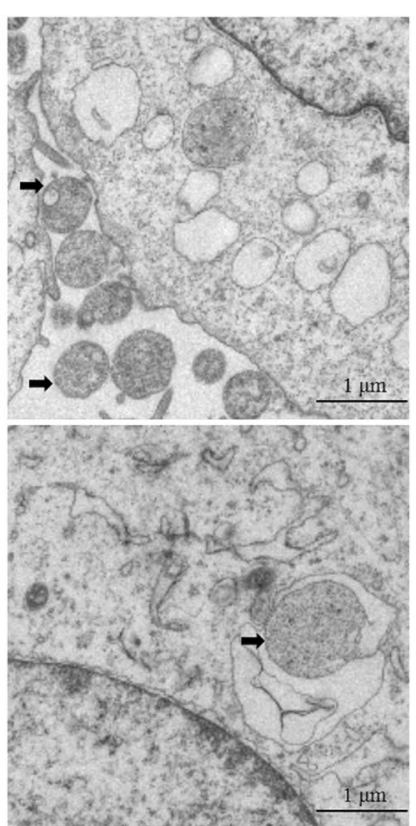

Figure 1 Cell infection model constructed. A Schematic overview. GM: gentamicin; stage I: bMEC infected (Time = 0 h) with M. bovis inoculum at MOI of 1:30 for $1 \mathrm{~h}$; stage II: extracellular M. bovis were killed by addition of $2 \mathrm{~mL} /$ well DMEM with $400 \mu \mathrm{g} / \mathrm{mL}$ gentamicin for $2 \mathrm{~h}$ at $37^{\circ} \mathrm{C}$; stage III: fresh DMEM with $10 \%$ fetal bovine serum (FBS) and $20 \mu \mathrm{g} / \mathrm{mL}$ gentamicin were added to the infected cells. MOl: multiplicity of infection. B Replication of intracellular M. bovis in the cell infection model. C Ultra-microstructure observation of adherent M. bovis. D Ultra-microstructure observation of intracellular M. bovis. Arrows point to M. bovis. Data are mean \pm SD of 3 independent experiments. Standard deviations of individual measurements are indicated as bars. ${ }^{*}$ Compared to the control group $(p<0.05)$.

with $10 \%$ fetal bovine serum (FBS) and $20 \mu \mathrm{g} / \mathrm{mL}$ gentamicin was added to the infected cells, $2 \mathrm{~mL} /$ well (time $=1 \mathrm{~h})$.

\section{Enumerating intracellular $M$. bovis}

At designated time points, cells were washed thrice with PBS after treatment, as described above and the CFU were enumerated as described [18]. Cells were detached from plates with a 23-gauge needle and syringe; thereafter, bacterial concentrations were confirmed by plating ten-fold serial dilutions [18]. Fold changes in intracellular $M$. bovis loading were defined as the number of intracellular $M$. bovis at a subsequent time point, divided by the number of intracellular $M$. bovis at $3 \mathrm{hpi}$. The assay was repeated 3 times independently, with 3 biological replicates for each treatment. To enumerate CFU, M. bovis in each cell well were counted, with 6 repeats on plates.

\section{Transfection}

The GFP-LC3B assay is used widely to monitor autophagy or colocalization with cargo [26, 27]. AdGFP-LC3B is an adenovirus expressing GFP-LC3B fusion protein, whereas Ad-mCherry-GFP-LC3B expresses mCherry-GFP-LC3B fusion protein [26]; both were used, in accordance with the manufacturer's instructions, to transfect bMEC. Briefly, the bMEC were seeded on 6-well plates with coverslips, followed by incubation in $5 \% \mathrm{CO}_{2}$ at $37{ }^{\circ} \mathrm{C}$ for $12 \mathrm{~h}$. When bMEC density was $40-50 \%$ confluence, cells were infected with Ad-mCherry-GFP-LC3B or Ad-GFP-LC3B at MOI of 1:10 in DMEM containing $10 \%$ FBS. Then, cells were incubated in $5 \% \mathrm{CO}_{2}$ at $37{ }^{\circ} \mathrm{C}$ for $24 \mathrm{~h}$. Subsequently, these cells were used in infection experiments. Ad-mCherry-GFP-LC3B was used to demonstrate blockage of the autophagic flux in eukaryocytes [26]. Infection of Ad-mCherry-GFP-LC3B resulted in overexpression of tandem $\mathrm{mRFP} / \mathrm{mCherry-GFP}$ proteins. In cells lacking an autophagic state, mCherry-GFP-LC3B was present in the cytoplasm as diffuse yellow fluorescence (combined effects of mCherry and GFP). However, in infected cells under an autophagic state, mCherryGFP-LC3B targeted the autophagic substrate to form $\mathrm{mRFP} / \mathrm{mCherry}$ puncta. The GFP is sensitive to low $\mathrm{pH}$ and the GFP signal is quenched in an acidic or mature autophagosome. The mCherry is stable when exposed to an acidic environment; therefore, quenching the GFP signal causes an LC3B puncta with mCherry signal only. When imaged under confocal microscopy, the mCherryGFP-LC3B puncta will yield a red shift signal, indicating the autophagy flux was complete. However, if the autophagy flux is blocked, autophagosome maturation 
is inhibited and mCherry-GFP-LC3B produces yellow puncta. The bMEC were scanned with a Nikon A1 LFOV confocal microscope and numbers of RFP and GFP puncta were calculated [26, 28]. Twenty cells for each sample and at least 60 cells in each group were used for statistical analyses.

\section{Lyso-tracker red staining}

Lyso-Tracker Red staining was used to detect acidification of lysosomes or mature autophagosomes [26]. LysoTracker Red is based on DND-99, which is sensitive to a low $\mathrm{pH}$. Lysosomes or mature autophagosomes marked by Lyso-Tracker Red yield red structures when acidification is activated. At designated time points, bMEC were stained with Lyso-Tracker Red. Briefly, cells were incubated with $50 \mathrm{nM}$ Lyso-Tracker Red at $37^{\circ} \mathrm{C}$ for $30 \mathrm{~min}$ and the fluorescence signal of Lyso-Tracker Red was observed at $0,1,3,6,9,12$, and 24 hpi with a Nikon A1 LFOV confocal microscope. Randomly selected 5 fields per sample were analyzed for each sample and 3 repeats were conducted.

\section{Induction and inhibition of autophagy}

Following infection as described above, autophagy was induced by treatment with $20 \mu \mathrm{g} / \mathrm{mL}$ rapamycin or Hanks' balanced salt solution (HBSS). Alternatively, autophagy was inhibited by pre-incubating bMEC with $5 \mathrm{mM}$ 3-methyladenine (3-Ma) in full-nutrition medium for $3 \mathrm{~h}$ prior to infection. Moreover, effects of rapamycin and 3-Ma on $M$. bovis viability were determined. Specifically, $1 \times 10^{6} \mathrm{CFU} / \mathrm{mL} M$. bovis was incubated in PPLO medium with $20 \%$ horse serum, with or without 1 of the 2 compounds. The CFU of $M$. bovis was determined as described above, after incubation in $5 \% \mathrm{CO}_{2}$ at $37{ }^{\circ} \mathrm{C}$ for $24 \mathrm{~h}$. Effects of rapamycin or 3-Ma on viability of bMEC was evaluated with CCK-8 assays [27]. Briefly, bMEC were seeded in 96-well plates $\left(1 \times 10^{4}\right.$ cells/well $)$ in $100 \mu \mathrm{L}$ DMEM with $10 \%$ FBS. After incubation in $5 \%$ $\mathrm{CO}_{2}$ at $37^{\circ} \mathrm{C}$ for $24 \mathrm{~h}$, cells reached $60-70 \%$ confluence. Cells were treated with rapamycin $(20 \mu \mathrm{g} / \mathrm{mL}$ in DMEM with $10 \% \mathrm{FBS}$ ), or $3-\mathrm{Ma}$ (5 mM in DMEM with $10 \% \mathrm{FBS}$ ) or nothing (Control), followed by $24 \mathrm{~h}$ incubation in $5 \%$ $\mathrm{CO}_{2}$ at $37^{\circ} \mathrm{C}$. Then, fresh DMEM containing $10 \%$ CCK- 8 was placed in the well. The cells were incubated in $5 \%$ $\mathrm{CO}_{2}$ at $37^{\circ} \mathrm{C}$ for $2 \mathrm{~h}$ and optical density was determined with a microplate reader (Bio-Rad, Hercules, CA, USA) at $450 \mathrm{~nm}$. The density of treated cells relative to control cells was calculated.

\section{Western blotting}

At designated time points, cells were washed 3 times with PBS and total protein extracted with RIPA lysis buffer on ice. The liquid was centrifuged at $12000 \times g$ for $15 \mathrm{~min}$.
Protein concentrations were determined with a BCA protein assay kit, according to the manufacturer's instructions. For each sample, equal amounts of protein were separated by SDS-PAGE. Subsequently, proteins were transferred onto a PVDF using a semidry blotting system. Blots were first blocked with 5\% skim milk in Tween-20/ TBS (TBST) at room temperature for $2 \mathrm{~h}$, followed by 3 washes in TBST for $10 \mathrm{~min}$ each; then, membranes were incubated with each specific primary antibody overnight at $4{ }^{\circ} \mathrm{C}$. After 3 washes in TBST for 10 min each, membranes were incubated with secondary antibodies for $1 \mathrm{~h}$ at room temperature (RT). Signals were detected using an ECL-Plus Western blot detection system and band density analyzed with Image J (National Institutes of Health, Bethesda, MD, USA).

\section{RNA extraction, CDNA synthesis and real-time PCR}

At the various time points indicated, bMEC were harvested with $1 \mathrm{~mL}$ TransZol Up lysis solution (TransGen Biotech, Beijing, China). Total RNA was extracted with a total RNA extraction kit (TransGen Biotech), according to the manufacturer's instructions. The cDNA was synthesized using TransScript ${ }^{\circledR}$ II All-in-One First-Strand cDNA Synthesis SuperMix for PCR (TransGen Biotech). Both RNA and cDNA were quantified with a NanoDrop One spectrophotometer (Thermo Fisher Scientific, Waltham, MA, USA). For autophagy-associated genes, mRNA expression levels were verified with real time PCR. This assay included the following steps: pre-denaturation at $94{ }^{\circ} \mathrm{C}$ for $2 \mathrm{~min}$, followed by 40 cycles of denaturation at $95{ }^{\circ} \mathrm{C}$ for $5 \mathrm{~s}$ and annealing at $60{ }^{\circ} \mathrm{C}$ for $60 \mathrm{~s}$ using the Applied Biosystems StepOnePlus Real Time PCR system (Thermo Fisher Scientific). For melt curve analysis, PCR products were heated from 55 to $95{ }^{\circ} \mathrm{C}$, with the fluorescence signal checked every $0.5{ }^{\circ} \mathrm{C}$ to verify the specificity of each pair of primers. Cycle threshold $(\mathrm{Ct})$ values were determined with StepOne TM Software version 2.3 (Thermo Fisher Scientific). In this study, $\Delta \mathrm{Ct}=\mathrm{Ct}$ target gene $-\mathrm{Ct}$ endogenous control (arithmetic mean of the reference gene), whereas $\Delta \Delta \mathrm{Ct}=$ $\Delta \mathrm{Ct}$ sample $-\mathrm{Ct}$ control (uninfected cells). To visualize impacts of $M$. bovis on the responses of target genes in bMEC, relative mRNA expression data were presented as $2^{-\Delta \Delta C t}$. Real-time quantitative PCR was used to amplify $100 \mathrm{ng}$ of cDNA using the following pairs of primers: cattle LC3B upstream primer $5^{\prime}$-atgccgtccgagaaaacctt- $3^{\prime}$ and downstream primer $5^{\prime}$-ccgggattttggtaggatgc $-3^{\prime}$; cattle P62 upstream primer $5^{\prime}$-tctgccetgactacgaccta- $3^{\prime}$ and downstream primer $5^{\prime}$-ccatgtttcagcttccggag- $3^{\prime}$; cattle Beclin1 upstream primer $5^{\prime}$-gacactcagctcaacgtcac- $3^{\prime}$ and downstream primer $5^{\prime}$-gcttcctcctgatccaacct- $3^{\prime}$; cattle Lamp2a upstream primer $5^{\prime}$-ccgtgtctggagcatttcag- $3^{\prime}$ and downstream primer $5^{\prime}$-ggtgtcatcatccagcgaac- $3^{\prime}$; cattle GAPDH 
upstream primer $5^{\prime}$-attgaccttcactacatggt- $3^{\prime}$ and downstream primer $5^{\prime}$-acccttcaagtgagccccag- $3^{\prime}$. For these studies, GAPDH was the reference gene.

\section{Transmission electron microscopy}

The bMEC were digested with trypsin and centrifuged at $1000 \times g$ for $5 \mathrm{~min}$. The cells were washed twice with PBS, fixed with $2.5 \%$ glutaraldehyde for at least $2 \mathrm{~h}$, then fixed in $1 \%$ osmium tetroxide for $2 \mathrm{~h}$ at $4{ }^{\circ} \mathrm{C}$. After dehydration in a graded ethanol series, samples were embedded in epoxy resin-acetone mixtures for $2 \mathrm{~h}$, followed by immersion in a pure resin solution overnight at $37{ }^{\circ} \mathrm{C}$. After polymerization, ultrathin sections were cut, stained with saturated uranyl acetate in 50\% ethanol and lead citrate, and examined with a transmission electron microscope (JEM-1400, JEOL, Tokyo, Japan).

\section{Immunofluorescence staining and fluorescence microscopy}

To assess co-localization of autophagy-associated genes with intracellular M. bovis, LC3B, Lamp-2a or M. bovis were detected by immunofluorescence staining and confocal laser microscopy [29]. Cells on coverslips were fixed with $4 \%$ paraformaldehyde (PFA) for $15 \mathrm{~min}$ at RT, then washed twice with PBS. Fixed cells were blocked with $3 \%$ bovine serum albumin (BSA) in PBS for $15 \mathrm{~min}$, followed by permeabilization with $0.2 \%$ Triton X-100 in PBS for $45 \mathrm{~min}$ at room temperature. Afterwards, cells were incubated with an appropriate antibody for $1 \mathrm{~h}$ at room temperature, washed 3 times with PBS, then incubated with Alexa Fluor-conjugated secondary antibodies for $0.5 \mathrm{~h}$ at RT. Finally, coverslips were stained with fluorescence mounting medium containing DAPI and mounted on glass slides. Images were captured with a Nikon A1 LFOV confocal microscope at laser wavelengths of 405, 561 and $488 \mathrm{~nm}$ and analyzed with Image J software with the JaCoP plugin. Representative cells were selected and photographed. Twenty cells for each sample and at least 60 cells in each group were used for statistical analyses.

\section{Statistical analyses}

All assays were repeated 3 times independently, unless otherwise stated. There were 3 biological replicates in every treatment, unless otherwise stated. All data were analyzed by 1-way ANOVA using SPSS 22.0 (IBM Corp., Armonk, NY, USA) and data reported as mean \pm standard deviation of 3 independent experiments.

\section{Results}

\section{M. bovis survival patterns in infected bMEC}

The bMEC were identified by CK18 staining. The proportion of CK18-positive cells was > 95\% in cells from passages 6-9 (Additional file 1). There was no significant difference between the purity of bMEC in passage 6 versus passages 7-9 (Additional file $1, p<0.05$ ) and bMEC from passages 6-8 were used for experiments. When bMEC infected by $M$. bovis were assessed by TEM at $1 \mathrm{hpi}$, some $M$. bovis were adherent on the surface of bMEC (Figure 1C), whereas intracellular M. bovis were in a membrane-like structure (Figure 1D). The intracellular $M$. bovis load in bMEC at 9 hpi decreased $(p<0.05)$ to approximately half that at $3 \mathrm{hpi}$, although intracellular $M$. bovis increased at $24 \mathrm{hpi}$ (Figure 1B; $p<0.05$ ).

\section{M. bovis induced autophagy in bMEC}

Protein levels of autophagy-associated genes were analyzed by Western blotting. There was increased conversion of LC3I-LC3II from 3 to $12 \mathrm{hpi}$ in infected bMEC compared to control (uninfected) cells (Figure 2A, B; $p$ $<0.05)$. Levels of P62 protein were decreased in infected cells compared to control cells at 1,3 , and 6 hpi (Figure 2A, C; $p<0.05)$. Furthermore, Beclin1 was higher in infected cells compared to control cells at 3 and 6 hpi (Figure 2D, E; $p<0.05$ ). Relative mRNA expression levels of autophagy-associated genes were tested by RT-PCR. There were higher levels of mRNA for LC3B and Beclin1 in infected cells compared to control cells at 1, 3 and 6 hpi (Figure 3A, C; $p<0.05$ ). However, mRNA levels of the 2 autophagy indicators were lower in infected versus control cells at 12 and 24 hpi (Figure 3A, C; $p<0.05$ ). The relative mRNA expression levels of P62 and Lamp2a were increased in infected cells compared to control cells at $1,3,6,12$, and 24 hpi (Figure 3B, D; $p<0.05$ ). The autophagy flux was analyzed with an mRFP-GFPLC3 adenovirus reporter and confocal microscope. Accumulation of LC3 puncta occurred in infected bMEC, whereas there was a diffuse distribution of LC3 in control cells (Figure 4A). Levels of total $\mathrm{mRFP}^{+} \mathrm{GFP}^{+} \mathrm{LC} 3$ puncta (yellow signal) were higher in infected cells at $1 \mathrm{hpi}$, compared to control cells at $0 \mathrm{hpi}$ (Figure 4B; $p$ $<0.05)$. Therefore, M. bovis induced autophagy in bMEC at 1 and 3 hpi.

\section{Autophagy flux was blocked}

The level of P62 protein underwent a transient decline at 1 hpi $(p<0.05)$, followed by a time-dependent increase from 3 to 12 hpi (Figures. 2A, C; $p<0.05$ ). However, levels of P62 mRNA increased in infected cells after 1 hpi (Figure 3B; $p<0.05$ ). Decreases in P62 protein levels at 1,3 and 6 hpi were attributed to autophagic degradation, whereas gradually restored levels of P62 implied that the autophagy flux was blocked at 12 and 24 hpi. AdmCherry-GFP-LC3 was used to monitor the autophagic flux in bMEC. The mRFP ${ }^{+} \mathrm{GFP}^{-} \mathrm{LC} 3$ puncta (red signal), which yielded no or weak GFP signals, increased in infected cells at 1 and $3 \mathrm{hpi}$, compared to control cells 


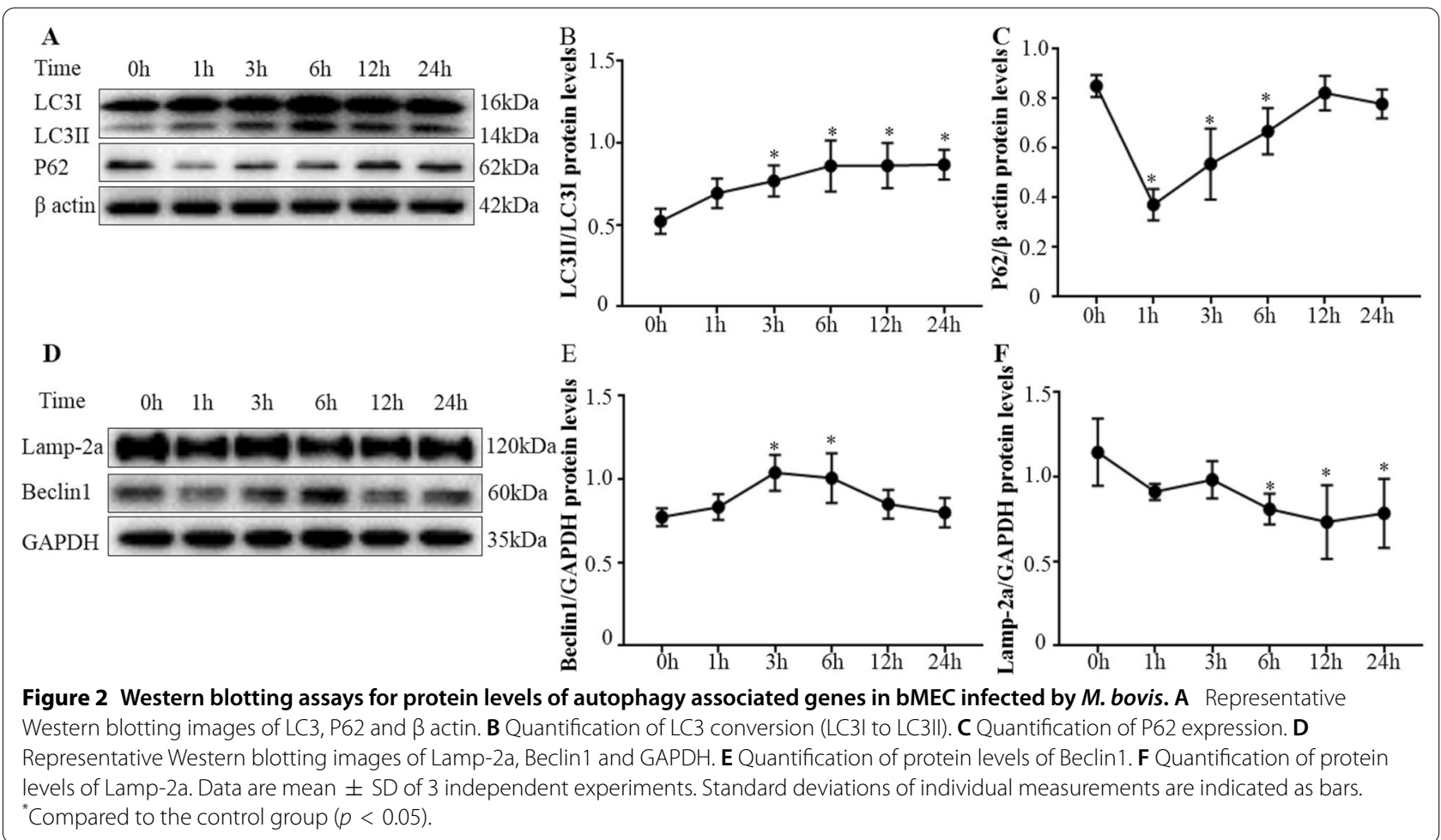

at 0 hpi (Figure 4B; $\mathrm{p}<0.05$ ). However, the subsequent $\mathrm{mRFP}^{+} \mathrm{GFP}^{-} \mathrm{LC} 3$ puncta levels in infected cells at 6, 12 and 24 hpi decreased to levels not significantly different from control cells (Figure 4B). Therefore, autophagosome maturation was inhibited at 6,12 and $24 \mathrm{hpi}$. Levels of Beclin1 mRNA and protein increased at 3 and 6 hpi compared to control bMEC $(0 \mathrm{~h})(p<0.05)$, then decreased at 12 and $24 \mathrm{hpi}$, indicating defective delivery of lysosomal cargo at the later stages (Figures 2D, F, 3C). Overall, there was clear evidence that the autophagy flux was blocked at 12 and $24 \mathrm{hpi}$ in infected bMEC.

\section{Lysosomes were impaired by M. bovis infection}

When an autophagy flux is induced, following expansion and closure of the phagopore, an autophagosome matures and forms an autophagolysosome. In many cases, microorganisms internalized by eukaryotic cells are efficiently eliminated in a mature autophagolysosome, which contains lysosomal hydrolases, e.g., lysosomal-associated membrane glycoproteins (LAMP) [5]. These lysosomal hydrolases are responsible for degradation of autophagic substrates. In the present study, levels of Lamp-2a protein were decreased at 6, 12 and 24 hpi compared to cells at 0 hpi (Figure 2D, F; $p<0.05$ ).
Autophagosome acidification was assessed by fluorescence microscopy. Acidified lysosomes probed by LysoTracker Red yielded a red signal, whereas intracellular DNA particles were stained with DAPI [14]. Based on the evaluation of randomly selected fields, red fluorescence was reduced around intracellular $M$. bovis, indicating that $M$. bovis infection inhibited autophagosome acidification (Figure 5). The results indicate that the lysosomes in bMEC were impaired at 6, 12 and $24 \mathrm{hpi}$.

\section{Induction of autophagy promotes maturation of phagosomes, resulting in inhibition of intracellular $M$. bovis replication}

To assess effects of autophagy on intracellular M. bovis replication, autophagy in $M$. bovis-infected bMEC was induced by rapamycin or HBSS, or inhibited by 3-Ma. Intracellular $M$. bovis was marked by immunostaining with mouse anti-M. bovis serum, prepared as described above. Inhibition of autophagosomes was apparent at $6 \mathrm{hpi}$; therefore, samples were collected at $6 \mathrm{hpi}$ and cells were sequentially assessed with fluorescence microscopy. Images were analyzed with Image J software with the JaCoP plugin. Co-localization of LC3 and $M$. bovis indicate that the LC3-positive $M$. 

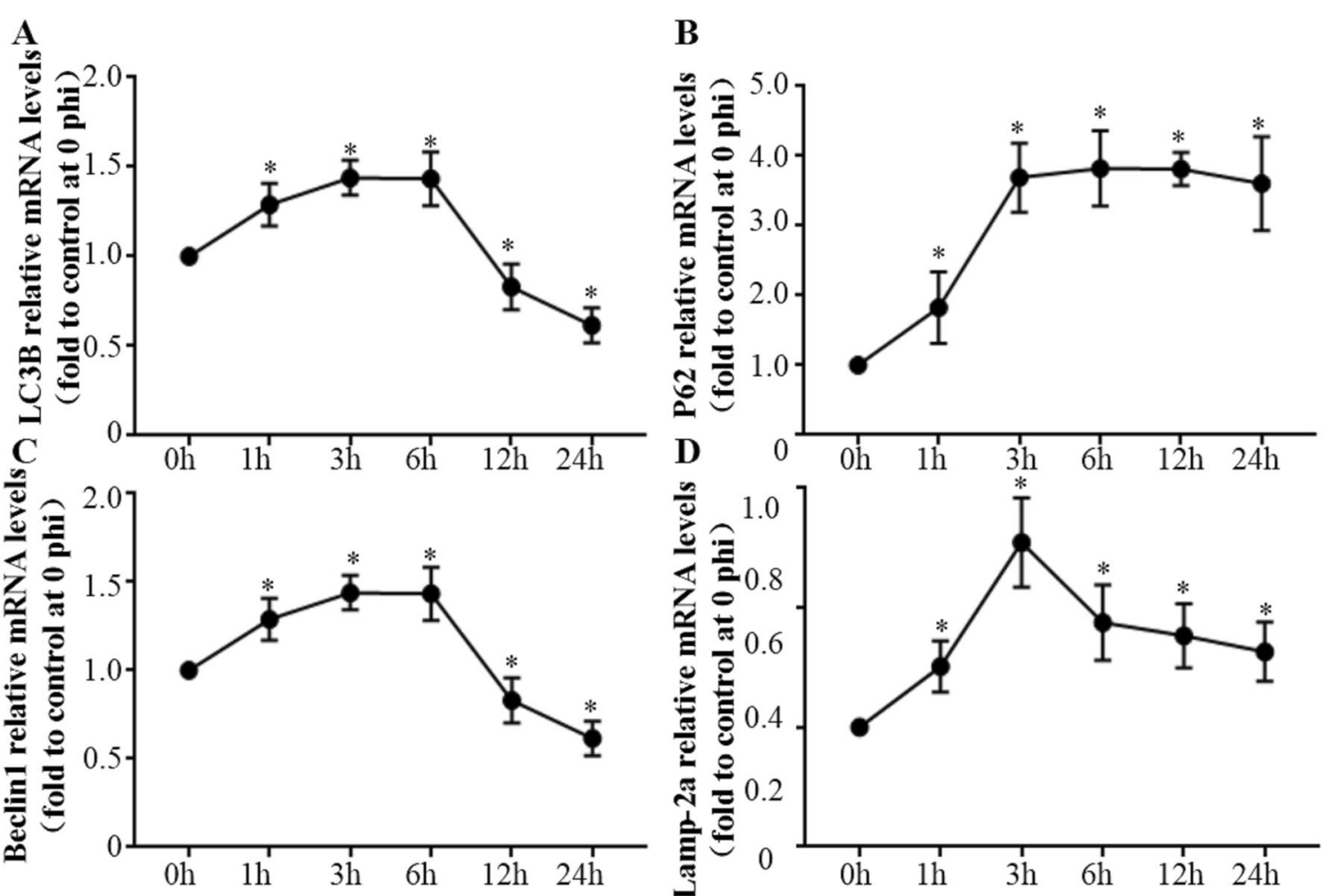

Figure 3 RT-PCR assays for mRNA expression changes in autophagy-associated genes in bMEC infected by M. bovis. A Relative mRNA expression levels of LC3B. B Relative mRNA expression levels of P62. C Relative mRNA expression levels of Beclin1. D Relative mRNA expression levels of Lamp-2a. Data are mean \pm SD of 3 independent experiments. Standard deviations of individual measurements are indicated as bars. ${ }^{*}$ Compared to the control group $(p<0.05)$.

bovis proportions were higher in HBSS or rapamycintreated cells compared to the control cells (infected with $M$. bovis but not treated with rapamycin, HBSS or 3-Ma; Figure 6; $p<0.05$ ), but were lower in 3-Ma treated cells (Figure 6; $p<0.05$ ). Subsequently, colocalization of Lamp-2a and M. bovis were assessed by fluorescence microscopy and intracellular $M$. bovis enumerated. Both rapamycin and HBSS significantly increased the Lamp-2a positive M. bovis proportions in bMEC compared to the control cells $(p<0.05)$, whereas it was decreased by 3 -Ma (Figure 7; $p<0.05$ ). Non-treated cells (NT, bMECs were not treated with rapamycin, HBSS, 3-Ma or infection) had low levels of red signal, indicating the good specificity of the immunostaining methods by using the mouse anti-M. bovis serum (Figs. 6A, 7A). The cells at 24 hpi were collected as samples for enumerating intracellular $M$. bovis. The intracellular $M$. bovis load was significantly decreased in cells treated with rapamycin or HBSS, whereas it was increased by 3 -Ma (Figure $8 ; p<0.05$ ). Effects of rapamycin and 3-Ma on $M$. bovis viability were tested. These 2 compounds did not decrease viability of $M$. bovis in PPLO medium (Additional file 2A; $p<0.05$ ). Similarly, the effects of rapamycin and 3-Ma on bMEC viability were also tested; neither of these 2 compounds decreased viability of bMEC in DMEM containing 10\% FBS (Additional file 2B; $p<0.05$ ).

\section{Discussion}

Autophagy is not only a conserved catabolic pathway for recycling intracellular materials, but also a defensive strategy used by eukaryotic cells to degrade intracellular pathogens such as Staphylococcus aureus and $M$. tuberculosis. In contrast, there is emerging evidence that autophagy enables some bacteria (e.g., Salmonella) to 


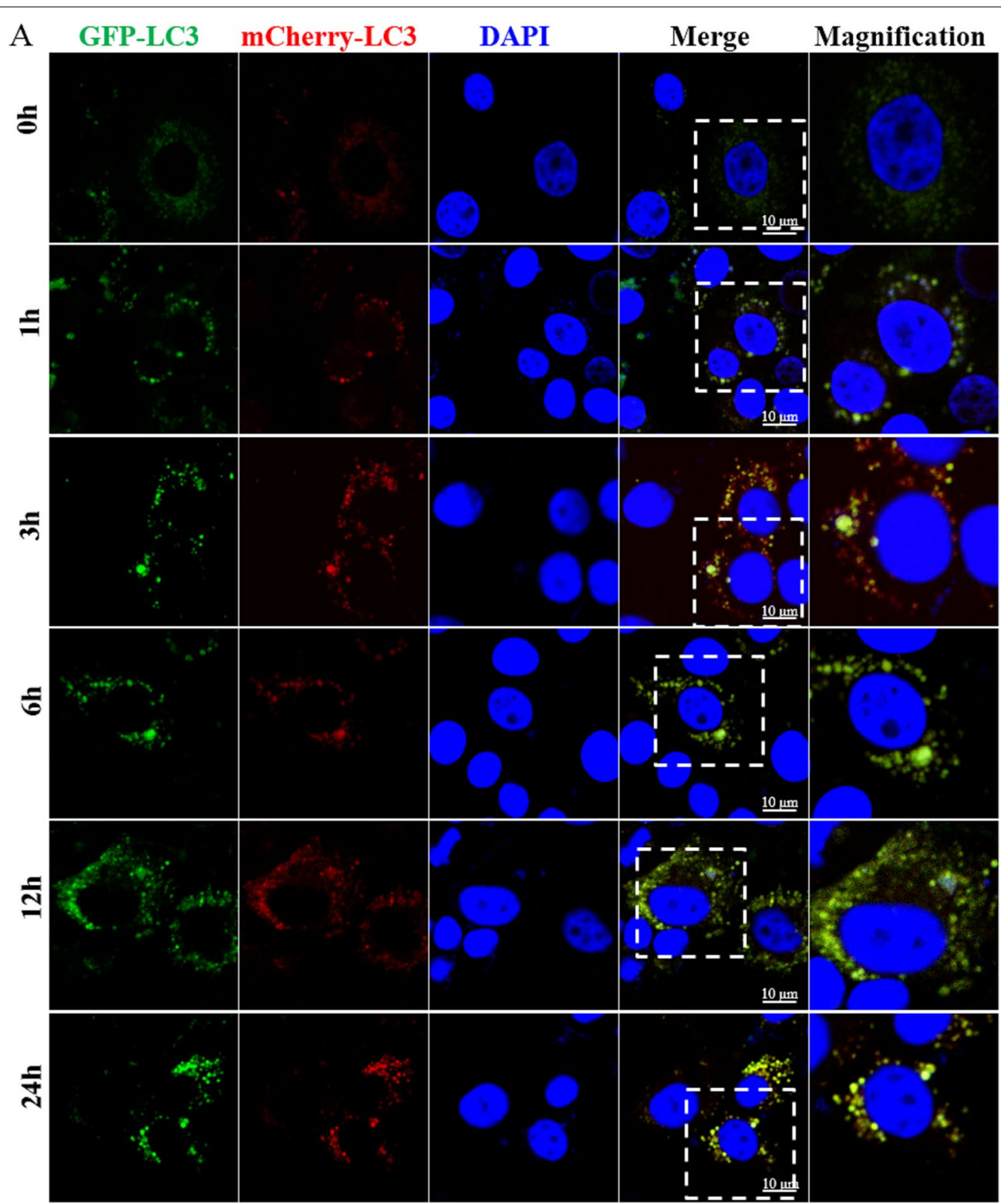

B

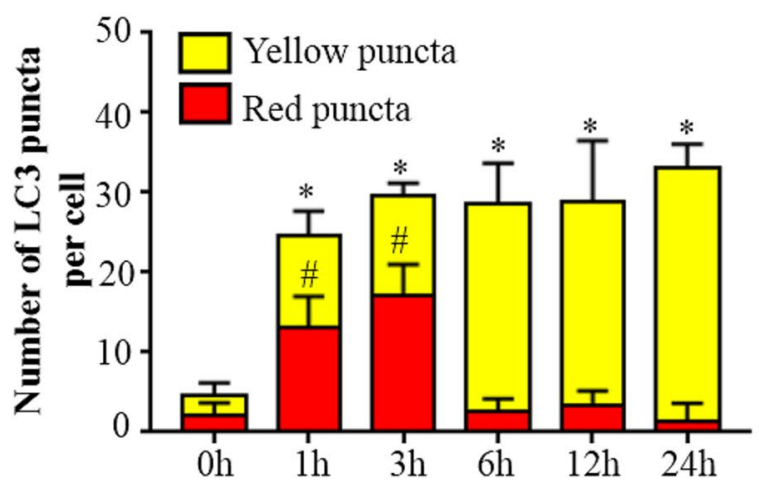

Figure 4 Laser confocal analysis of autophagy flux assessed by Ad-mCherry-GFP-LC3. A Representative images of mCherry-GFP-LC3 in bMEC. bMEC transfected by Ad-mCherry-GFP-LC3 were infected by M. bovis. The autophagy flux was analyzed by a laser confocal method. The mRFP ${ }^{+} G F P^{-}$LC3 puncta yielded a red signal, whereas the mRFP+ GFP ${ }^{+}$LC3 yielded a yellow signal. B Quantification of autophagosomes in bMEC. Twenty cells for each sample and at least 60 cells in each group were used for statistical analyses. SD of 3 independent experiments. Standard deviations of individual measurements are indicated as bars. ${ }^{*}$ Compared to the control group $(p<0.05)$. 


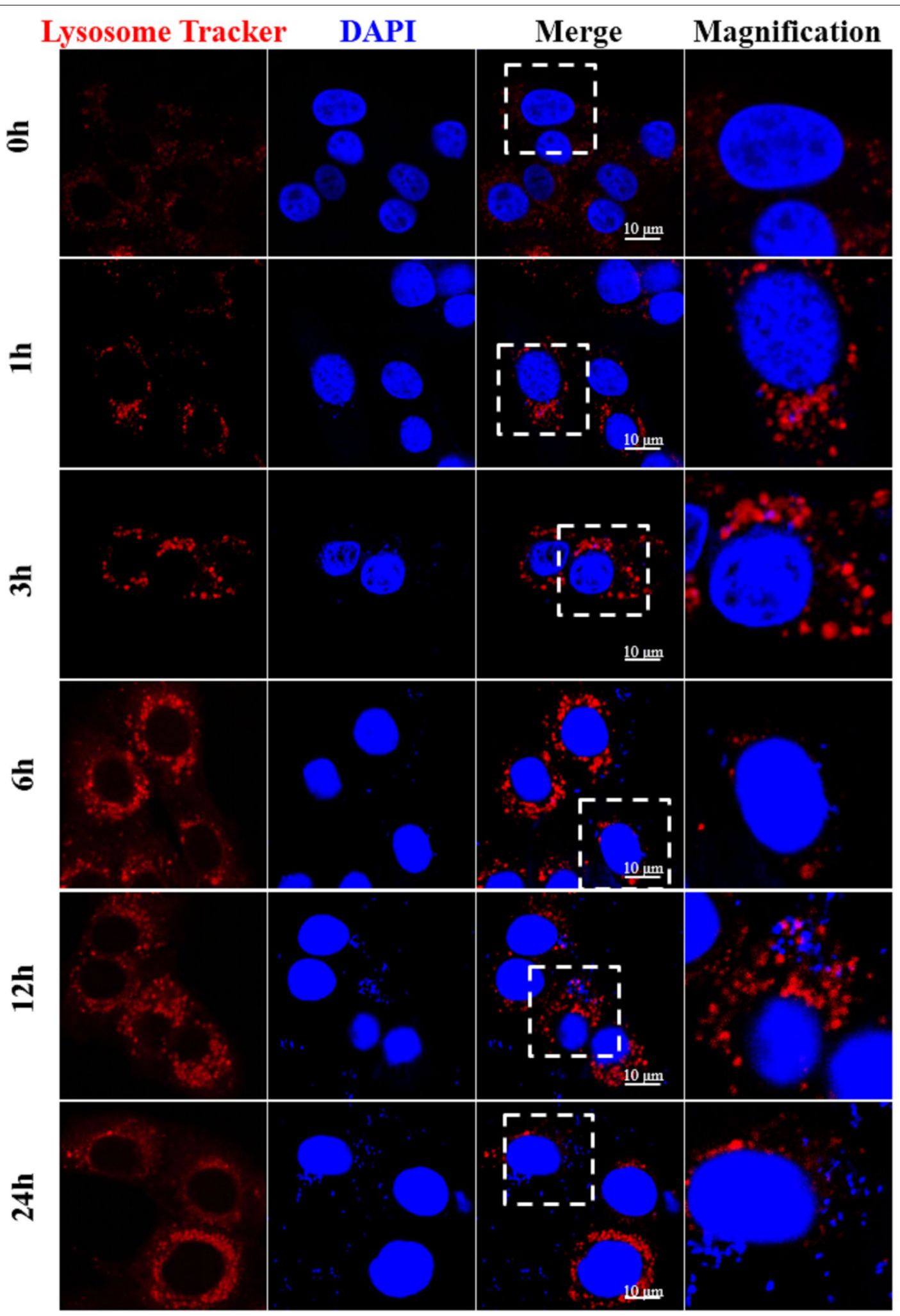

Figure 5 Lysosomal acidification assays in bMEC infected by $\boldsymbol{M}$. bovis. Lysosomes in bMEC were stained by Lysotracker Red prior to fixation after infection. Acidified lysosomes were marked by a pH sensitive probe; the red signal indicates acidified lysosomes. Five randomly selected fields per sample were analyzed for each sample and 3 repeats were conducted. A representative field is shown in the figure. 
replicate in host cells [5]. However, there are limited data regarding autophagy during infections with Mycoplasma species, the smallest self-replicating microorganisms. In this study, $M$. bovis and bMEC were used to establish an in vitro model to analyze effects of autophagy on nonspecialized phagocytes on the intracellular replication of mycoplasma. This study was the first to document that: (1) $M$. bovis induced autophagy in a nonprofessional phagocytic cell; (2) the autophagy flux was subsequently blocked by $M$. bovis; and (3) M. bovis subverted the autophagosome to promote intracellular replication in bMEC. Therefore, our hypothesis that $M$. bovis subverts autophagy to promote its intracellular replication was supported.

An in vitro infection model with $M$. bovis and primary bMEC was established in this study. M. bovis can invade many types of cells, including epithelial cells and lymphocytes [18-20]. Therefore, this pathogen can effectively evade humoral immunity and bactericidal effects of certain antibiotics, enabling it to persist in the host [18]. Adhesion and invasion of $M$. bovis are crucial to successful infection. Furthermore, it was speculated that M. bovis invasion into epithelial cells occurs mainly through endocytosis [18]. In our previous study, adhesion and invasion of $M$. bovis were verified with an infection model using MAC-T cells, a bovine mammary gland epithelial cell line [17]. However, effects of autophagy on intracellular $M$. bovis were not fully elucidated. In this study, primary bMEC were used. The purity of bMEC was analyzed by staining with CK18, a marker of luminal epithelial cells $[24,25]$. The purities of the bMEC in passage 6-9 were all over $95 \%$. The ability of $M$. bovis to adhere to the surface of bMEC and subsequently become intracellular was confirmed by TEM. Moreover, intracellular $M$. bovis was present in a membrane-like structure in the cytoplasm of bMEC. Hence, our in vitro infection model was successful. Based on slow-growth kinetics of $M$. bovis during the first $9 \mathrm{~h}$ of infection, we inferred that $M$. bovis replication was initially restricted. However, thereafter, numbers of intracellular $M$. bovis increased significantly. Thus, $M$. bovis survival and replication were restricted during the initial $9 \mathrm{~h}$ of infection in bMEC, but $M$. bovis replicated significantly thereafter, implying changes that produced a more favorable growth environment.

In this study, $M$. bovis activated autophagy in bMEC at early stages of infection. To avoid host autophagic defenses, pathogenic species have developed 3 strategies: evasion, inhibition, and subversion $[5,9]$. For example, a type III secretion system enables Shigella to avoid being detected by the host autophagic machinery [12]; Legionella pneumophila inhibits autophagy in mammalian cells [30]; and Staphylococcus aureus impairs autophagy for replication [28, 31]. Similarly, Mycoplasma pneumoniae induced autophagy in mice [14], whereas Mycoplasma ovipneumoniae activated autophagy in RAW 264.7 cells [13]. In this study, to investigate autophagy, the ultramicrostructure of intracellular $M$. bovis was investigated. There were visible membranes surrounding the $M$. bovis with cytoplasmic (membranous) material that may have resulted from intraluminal vesicle formation or from fusion with autophagic vesicles, consistent with previous studies of Staphylococcus aureus targeted by autophagy [27]. Secondly, increased turnover of LC3II (the most widely recognized molecular indicator of autophagy) and a transient decrease in P62 was induced by $M$. bovis at 1 hpi. Therefore, in the present study, $M$. bovis induced autophagy in bMEC when adhesion and invasion were successfully established.

However, the autophagic flux was subsequently blocked by $M$. bovis infection at later stages. Autophagic flux refers to the entire process of autophagy, including delivery of cargo to lysosomes and its subsequent breakdown $[32,33]$. To detect the autophagic flux in bMEC, P62 was analyzed by Western blotting and RT-PCR, followed by 


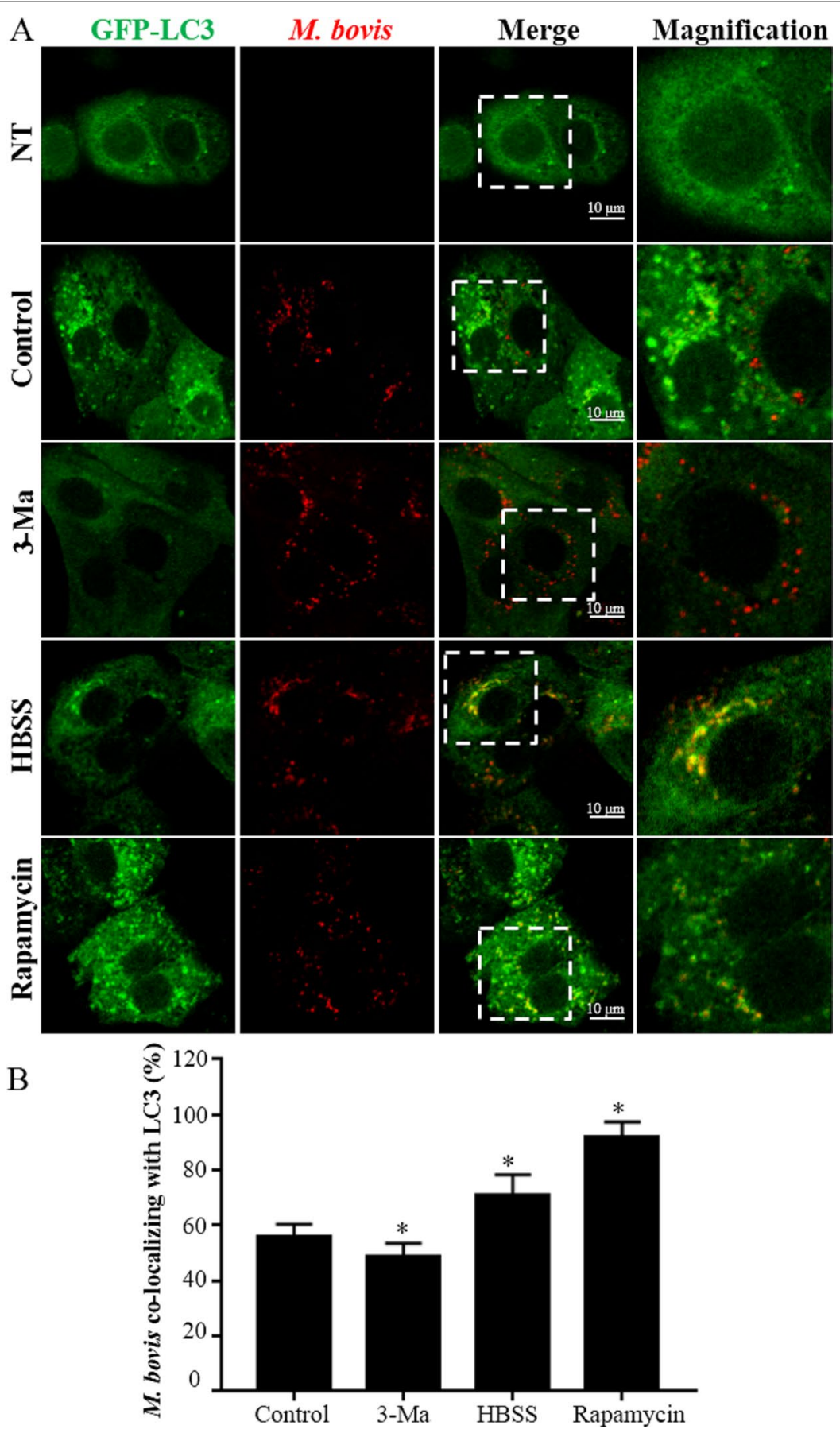

Figure 6 M. bovis translocate into autophagosomes indicated by M. bovis co-localizing with GFP-LC3. A Representative images of $M$. bovis (Red) co-localizing with GFP-LC3 (Green) at 6 hpi. bMECs transfected by ad-GFP-LC3 was infected by M. bovis. Autophagy was enhanced by rapamycin $(20 \mu \mathrm{g} / \mathrm{mL}$ ) or starvation (Hanks balanced salt solution) after infection. Autophagy was inhibited by pre-incubating bMEC with $5 \mathrm{mM}$ 3 -methyladenine in full nutrition medium for $3 \mathrm{~h}$ prior to infection. The cells on coverslips were fixed by $4 \%$ paraformaldehyde, blocked by $3 \%$ with BSA in PBS and permeabilized with $0.2 \%$ Triton X-100 in PBS. The M. bovis in cells were immunostained with mouse anti-M. bovis antibody and Alexa Fluor-conjugated secondary antibody. NT: bMEC without treatment of rapamycin, Hanks balanced salt solution, 3-methyladenine or infection; Control: M. bovis-infected bMEC without treatment of rapamycin, HBSS, 3-methyladenine; 3-Ma: M. bovis-infected bMEC treated with 3-methyladenine; HBSS: M. bovis-infected bMEC treated with Hanks balanced salt solution; Rapamycin: M. bovis-infected bMEC treated with rapamycin. B Quantification of M. bovis co-localizing with GFP-LC3. Images were analyzed quantitatively with Image J software with the JaCoP plugin. Twenty cells for each sample and at least 60 cells in each group were used for statistical analyses. Data are mean \pm SD of 3 independent experiments. Standard deviations of individual measurements are indicated as bars. ${ }^{*}$ Compared to the control group $(p<0.05)$. 
detection of LC3 puncta with fluorescence microscopy. Under normal circumstances, P62 is a link between LC3 and substrates, with P62 and P62-bound substrates incorporated into the completed autophagosome during the initial stage and subsequently degraded in autolysosomes. Therefore, increasing P62 protein levels are indicative of inhibition of autophagy flux [26, 34]. In this study, P62 protein levels decreased significantly during the early stage of infection (1 hpi), indicating activation of autophagy. However, continuous increases in expression of P62 mRNA and gradually restored P62 protein levels in bMEC indicate that the degradation of $\mathrm{P} 62$ protein was inhibited at 12 and $24 \mathrm{hpi}$. The $\mathrm{mRFP} / \mathrm{mCherry-}$ GFP method enabled concurrent assessment of both the induction of autophagy and the subsequent flux through autophagic compartments under native conditions [26]. The $\mathrm{mRFP}^{+} \mathrm{GFP}^{-} \mathrm{LC} 3$ puncta increased significantly in infected cells at 1 and $3 \mathrm{hpi}$, indicating that autophagosome maturation was activated. However, subsequent decreases in $\mathrm{mRFP}^{+} \mathrm{GFP}^{-} \mathrm{LC} 3$ puncta levels in infected cells at 6,12 and $24 \mathrm{hpi}$ indicate that autophagosome maturation was inhibited. Therefore, in bMEC infected with $M$. bovis, the autophagy flux was blocked at 12 and 24 hpi.

Maturation of the autophagosome was subverted in bMEC. An autophagosome is the core functional center for degradation of autophagy-targeted substrates [35, 36]. There is emerging evidence that some bacteria, e.g., Staphylococcus aureus and M. tuberculosis, induce defects in phagosome acidification $[11,31]$. In this study, levels of Beclin1 protein increased at 3 and $6 \mathrm{hpi}$, but subsequently decreased at 12 and $24 \mathrm{hpi}$, indicating a defect in delivery of lysosomal cargo. In addition, Lamp-2 protein levels decreased significantly at 6, 12 and $24 \mathrm{hpi}$, providing further evidence that lysosomal function was impaired by $M$. bovis infection.

Autophagy is an antibacterial defense [26]. For example, activated autophagy results in the reduced intracellular Mycoplasma ovipneumoniae in macrophage [13]. To confirm the relationship of autophagy and intracellular
M. bovis, bMEC were treated by starvation, rapamycin or 3-Ma. In this study, intracellular numbers of $M$. bovis were inversely associated with the level of autophagy in host cells, consistent with previous reports for Mycoplasma ovipneumoniae [13]. Moreover, both starvation and rapamycin increased the LC3 positive $M$. bovis proportions and the Lamp-2a positive $M$. bovis proportions, and decreased intracellular $M$. bovis replication in bMEC, whereas 3-Ma yielded opposite results. Therefore, we inferred that intracellular replication of $M$. bovis was regulated by autophagy, and under typical circumstances, it was promoted by blocking the delivery of $M$. bovis to the autophagosome and lysosome. Furthermore, activation of autophagy counteracted the $M$. bovis-induced blockade of phagosome maturation in bMEC. The outcome was similar to the $M$. tuberculosis variant bovis BCG, whereas Staphylococcus aureus had increasing loading of bacteria when autophagy was enhanced [5, 37]. An important limitation is that this study used an in vitro model that assessed the fate of intracellular $M$. bovis in bMEC, a non-specialized phagocyte. In contrast, under in vivo conditions, there would be more complex mechanisms, including host-pathogen interactions for other types of cells, including specialized phagocytes or immune cells. Host-Directed Therapy, based on modulation of autophagy, is a potential mechanism for effective clearance of infection [38]. Autophagy is a novel model to study intracellular biochemical mechanisms. Furthermore, modulation of autophagy following intracellular $M$ bovis infections provided insights into regulation of autophagy and indications of how $M$. bovis may induce persistent infections.

In conclusion, $M$. bovis infection induced autophagy in bMEC, but the ensuing autophagy flux was subsequently impaired by inhibiting maturation of autophagosomes. $M$. bovis subverted autophagy to promote its replication in $\mathrm{bMEC}$. These findings provide new knowledge and the impetus for additional studies to elucidate interactions between M. bovis and host cells. Perhaps in the future we 

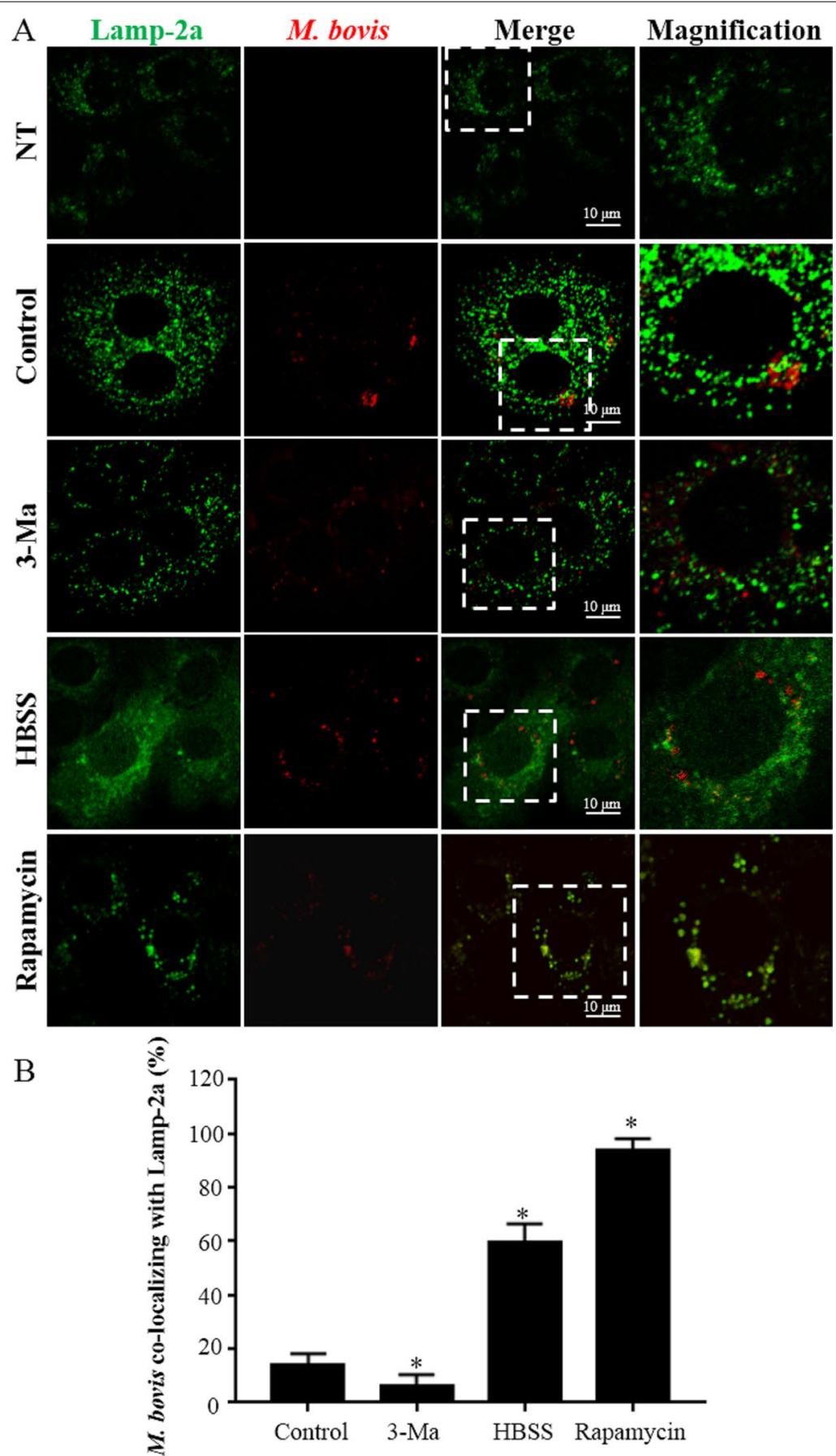

Figure 7 M. bovis translocate into lysosomes, as indicated by $\boldsymbol{M}$. bovis co-localizing with Lamp-2a. A Representative images of $M$. bovis (Red) co-localizing with Lamp-2a (Green) at 6 hpi. Autophagy was enhanced by rapamycin $(20 \mu \mathrm{g} / \mathrm{mL}$ ) or starvation (Hanks balanced salt solution). Autophagy was inhibited by pre-incubating the bMEC with $5 \mathrm{mM}$ 3-methyladenine in full nutrition medium for $3 \mathrm{~h}$ prior to infection. NT: bMEC without treatment of rapamycin, Hanks balanced salt solution, 3-methyladenine or infection; Control: M. bovis-infected bMEC without treatment of rapamycin, HBSS, 3-methyladenine; 3-Ma: M. bovis-infected bMEC treated with 3-methyladenine; HBSS: M. bovis-infected bMEC treated with Hanks balanced salt solution; Rapamycin: M. bovis-infected bMEC treated with rapamycin. B Quantification of M. bovis co-localizing with GFP-LC3. Images were analyzed quantitatively with Image I software with the JaCoP plugin. Twenty cells for each sample and at least 60 cells in each group were used for statistical analyses. Data are mean \pm SD of 3 independent experiments. Standard deviations of individual measurements are indicated as bars. ${ }^{*}$ Compared to the control group $(p<0.05)$. 


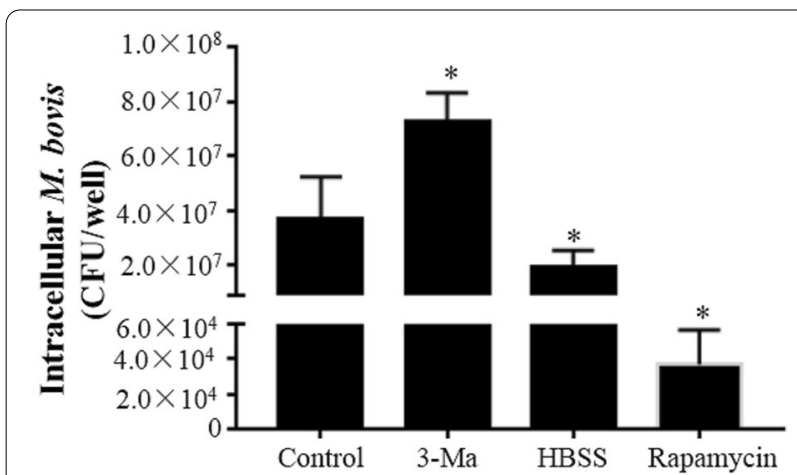

Figure 8 Intracellular M. bovis assays under various autophagic states. Intracellular M. bovis replication in bMEC under various autophagic states were compared. Control: $M$. bovis-infected bMEC without treatment of rapamycin, HBSS, 3-methyladenine; 3-Ma: M. bovis-infected bMEC treated with 3-methyladenine; HBSS: $M$. bovis-infected bMEC treated with Hanks balanced salt solution; Rapamycin: M. bovis-infected bMEC treated with rapamycin. Data are mean \pm SD of 3 independent experiments. Standard deviations of individual measurements are indicated as bars. ${ }^{*}$ Compared to the control group $(p<0.05)$.

can regulate autophagy to develop innovative therapies and perhaps improved vaccines.

\begin{abstract}
Abbreviations
bMEC: bovine mammary epithelial cells; MOl: multiplicity of infection; hpi: hours post-infection; HBSS: Hanks balanced salt solution; PFA: paraformaldehyde; BSA: bull serum albumin; 3-Ma: 3-Methyladenine; FBS: fetal bovine serum; GM: gentamicin; PBS: phosphate-buffered saline; LAMP: Iysosomalassociated membrane glycoproteins; TEM: transmission electron microscopy.
\end{abstract}

\section{Supplementary Information}

The online version contains supplementary material available at https://doi. org/10.1186/s13567-021-01002-z.

\section{Additional file 1 Identification of bMEC by staining with cytokera-} tin 18. A Representative images of randomly selected fields in bMEC from passages 6-9; bMEC were stained by cytokeratin 18 (CK18) and their nuclei were stained by DAPI; Arrows point to CK18 negative cells; $\mathbf{B}$ quantitative analysis of the bMEC from passages $6-9$; purity of bMEC was defined as the proportion of CK18 positive cells among total cells (stained by DAPI). Data are mean \pm SD of 3 independent experiments. Standard deviations of individual measurements are indicated as bars.

\section{Additional file 2 Effects of rapamycin and 3-methyladenine on $\mathbf{M}$.} bovis or bMEC. A Effects of rapamycin and 3-methyladenine on M. bovis viability in PPLO medium. B Effects of rapamycin and 3-methyladenine on viability of bMEC in DMEM medium containing $10 \%$ FBS by CCK- 8 assays. Data are mean \pm SD of 3 independent experiments. Standard deviations of individual measurements are indicated as bars. ${ }^{*}$ Compared to the control group $(P<0.05)$.

\section{Acknowledgements}

The authors thank our laboratory members who helped us to improve the research and the manuscript, with their skillful technical assistance, invaluable comments and suggestions.

\section{Authors' contributions}

$\mathrm{YL}, \mathrm{BH}$ and JG initiated the study, collated the data used, undertook the analysis and drafted the manuscript. YL, ZD, SX and GL contributed to the data collection and analysis. YL, YSL, SK, GL and WQ undertook surveys and/or contributed data to the study. YL, JPK, JG and BH contributed to analysis and manuscript preparation. All authors read and approved the final manuscript.

\section{Funding}

This study was financially supported by Ningxia Key R\&D Project (No.

2019BBF02027), Hebei Key R\&D Project (19226607D), the National Natural Science Foundation of China (No. 3217190391 and 31772813), the High-end Foreign Experts Recruitment Program (No. GDT20171100013).

\section{Availability of data and materials}

All data generated or analyzed during this study are included in this published article.

\section{Declarations}

Ethics approval and consent to participate

This work has received approval for research ethics from Ethical Committee of the College of Veterinary Medicine, China Agricultural University (CAU), Beijing and the study was conducted according to standard ethical guidelines implemented at CAU (SYXK, 2016-0008).

\section{Competing interests}

The authors declare that they have no competing interests.

\section{Author details}

${ }^{1}$ Department of Clinical Veterinary Medicine, College of Veterinary Medicine, China Agricultural University, Beijing 100193, China. ${ }^{2}$ College of Veterinary Medicine, Yunnan Agricultural University, Kunming 650201, Yunnan, China. ${ }^{3}$ Department of Production Animal Health, Faculty of Veterinary Medicine, University of Calgary, Calgary, AB T2N 4N1, Canada.

Received: 3 June 2021 Accepted: 30 August 2021

Published online: 14 October 2021

\section{References}

1. Dudek K, Nicholas RAJ, Szacawa E, Bednarek D (2020) Mycoplasma bovis infections-occurrence, diagnosis and control. Pathogens 9:640

2. Hutchison CA, Chuang RY, Noskov VN, Assad-Garcia N, DeerinckTJ, Ellisman MH, Gill J, Kannan K, Karas BJ, Ma L, Pelletier JF, Qi ZQ, Richter RA, Strychalski EA, Sun L, Suzuki Y, Tsvetanova B, Wise KS, Smith HO, Glass Jl, Merryman C, Gibson DG (2016) Design and synthesis of a minimal bacterial genome. Science 351:aad6253

3. Zhu X, Baranowski E, Dong Y, Li X, Hao Z, Zhao G, Zhang H, Lu D, Rasheed MA, Chen Y, Hu C, Chen H, Sagné E, Citti C, Guo A (2020) An emerging role for cyclic dinucleotide phosphodiesterase and nanoRNase activities in Mycoplasma bovis: securing survival in cell culture. PLoS Pathog 16:e1008661

4. Breuer M, Earnest TM, Merryman C, Wise KS, Sun L, Lynott MR, Hutchison CA, Smith HO, Lapek JD, Gonzalez DJ, Cre'cy-Lagard V, Haas D, Hanson AD, Labhsetwar P, Glass Jl, Luthey-Schulten Z (2019) Essential metabolism for a minimal cell. Elife 8:e36842

5. Sudhakar P, Jacomin A, Hautefort I, Samavedam S, Fatemian K, Ari E, Gul L, Amanda D, Jones E, Korcsmaros T, Nezis IP (2019) Targeted interplay between bacterial pathogens and host autophagy. Autophagy 15:1620-1633

6. Huang J, Brumell JH (2014) Bacteria-autophagy interplay: a battle for survival. Nat Rev Microbiol 12:101-114

7. Deretic V, Levine B (2018) Autophagy balances inflammation in innate immunity. Autophagy 14:243-251

8. Galluzzi L, Pedro J, Levine B, Green DR, Kroemer G (2017) Pharmacological modulation of autophagy: therapeutic potential and persisting obstacles. Nat Rev Drug Discov 16:487-511

9. Choi Y, Bowman JW, Jung JU (2018) Bacterial interaction with host autophagy. Nat Rev Microbiol 16:341-354 
10. Siqueira MS, Ribeiro RM, Travassos LH (2018) Autophagy and its interaction with intracellular bacterial pathogens. Front Immunol 9:935

11. Tateosian NL, Pellegrini JM, Amiano NO, Rolandelli A, Casco N, Palmero DJ, Colombo Ml, García VE (2017) IL17A augments autophagy in Mycobacterium tuberculosis-infected monocytes from patients with active tuberculosis in association with the severity of the disease. Autophagy 13:1191-1204

12. Bajunaid W, Haidar-Ahmad N, Kottarampatel AH, Manigat FO, Silué N, Tchagang CF, Tomaro K, Campbell-Valois F (2020) The T3SS of Shigella: expression, structure, function, and role in vacuole escape. Microorganism 8:1933

13. Luo HL, Wu X, Xu Z, Hao X, Wang Y, Li M (2020) NOD2/c-Jun NH2-Terminal kinase triggers Mycoplasma ovipneumoniae-induced macrophage autophagy. J Bacteriol 202:e00689-e719

14. Shimizu T, Kimura Y, Kida Y, Kuwano K, Tachibana M, Hashino M, Watarai M (2014) Cytadherence of Mycoplasma pneumoniae induces inflammatory responses through autophagy and toll-like receptor 4. Infect Immun 82:3076-3086

15. Nicholas RA, Fox LK, Lysnyansky I (2016) Mycoplasma mastitis in cattle: to cull or not to cull. Vet J 216:142-147

16. Liu Y, Xu S, Li M, Zhou M, Huo W, Gao J, Liu G, Kastelic JP, Han B (2020) Molecular characteristics and antibiotic susceptibility profiles of $\mathrm{MycO}-$ plasma bovis associated with mastitis on dairy farms in China. Prev Vet Med 182:105106

17. Liu Y, Zhou M, Xu S, Muhammad AK, Shi Y, Qu W, Gao J, Liu G, Kastelic JP, Han B (2020) Mycoplasma bovis-generated reactive oxygen species and induced apoptosis in bovine mammary epithelial cell cultures. J Dairy Sci 103:10429-10445

18. Bürki S, Gaschen V, Stoffel MH, Stojiljkovic A, Frey J, Kuehni-Boghenbor K, Pilo P (2015) Invasion and persistence of Mycoplasma bovis in embryonic calf turbinate cells. Vet Res 46:53

19. Josi C, Bürki S, Stojiljkovic A, Wellnitz O, Stoffel MH, Pilo P (2018) Bovine epithelial in vitro infection models for Mycoplasma bovis. Front Cell Infect Microbiol 8:329

20. van der Merwe J, Prysliak T, Perez-Casal J (2010) Invasion of bovine peripheral blood mononuclear cells and erythrocytes by Mycoplasma bovis. Infect Immun 78:4570-4578

21. Gondaira S, Nishi K, Fujiki J, Iwano H, Watanabe R, Egichi A, Hirano Y, Higuchi $H$, Nagahata $H$ (2021) Innate immune response in bovine neutrophils stimulated with Mycoplasma bovis. Vet Res 52:58

22. Wellnitz O, Kerr DE (2004) Cryopreserved bovine mammary cells to model epithelial response to infection. Vet Immunol Immunopathol 101:191-202

23. Zbinden C, Pilo P, Frey J, Bruckmaier RM, Wellnitz O (2015) The immune response of bovine mammary epithelial cells to live or heat-inactivated Mycoplasma bovis. Vet Microbiol 179:336-340

24. Baratta M, Volpe MG, Nucera D, Gabai G, Guzzo N, Fustini M, Martignani E (2015) Differential expression of living mammary epithelial cell subpopulations in milk during lactation in dairy cows. J Dairy Sci 98:6897-6904

25. Jin L, Qu Y, Gomez LJ, Chung S, Han B, Gao B, Yue Y, Gong Y, Liu X, Amersi F, Dang C, Giuliano AE, Cui X (2017) Characterization of primary human mammary epithelial cells isolated and propagated by conditional reprogrammed cell culture. Oncotarget 9:11503-11514

26. Klionsky DJ, Abdel-Aziz AK, Abdelfatah S, Abdellatif M, Abdoli A, Abel S, Abeliovich H, Abildgaard MH, Abudu YP, Acevedo-Arozena A, Adamopoulos IE, Adeli K, Adolph TE, Adornetto A, Aflaki E, Agam G, Agarwal A, Aggarwal BB, Agnello M, Agostinis P, Agrewala JN, Agrotis A, Aguilar PV, Ahmad ST, Ahmed ZM, Ahumada-Castro U, Aits S, Aizawa S, Akkoc Y, Akoumianaki T et al (2021) Guidelines for the use and interpretation of assays for monitoring autophagy (4th edition). Autophagy 17:1-382

27. Geng N, Wang X, Yu X, Wang R, Zhu Y, Zhang M, Liu J, Liu Y (2020) Staphylococcus aureus avoids autophagy clearance of bovine mammary epithelial cells by impairing lysosomal function. Front Immunol 11:746

28. Zhou F, Yang $X$, Zhao H, Liu Y, Feng Y, An R, Lv X, Li J, Chen B (2018) Downregulation of OGT promotes cisplatin resistance by inducing autophagy in ovarian cancer. Theranostics 8:5200-5212

29. Birmingham CL, Smith AC, Bakowski MA, Yoshimori T, Brumell JH (2006) Autophagy controls Salmonella infection in response to damage to the Salmonella-containing vacuole. J Biol Chem 281:11374-11383

30. Choy A, Dancourt J, Mugo B, O'Connor TJ, Isberg RR, Melia TJ, Roy CR (2012) The Legionella effector RavZ inhibits host autophagy through irreversible Atg8 deconjugation. Science 338:1072-1076

31. Missiakas D, WinstelV (2020) Selective host cell death by Staphylococcus aureus. Front Immunol 11:621733

32. Levine B, Kroemer $G$ (2019) Biological functions of autophagy genes: a disease perspective. Cell 176:11-42

33. Deretic V, Saitoh T, Akira S (2013) Autophagy in infection, inflammation, and immunity. Nat Rev Immunol 10:722-737

34. Goode A, Butler K, Long J, Cavey J, ScottD SB, Sollenberger J, Gell C, Johansen T, Oldham NJ, Searle MS, Layfield R (2016) Defective recognition of LC3B by mutant SQSTM1/p62 implicates impairment of autophagy as a pathogenic mechanism in ALS-FTLD. Autophagy 12:1094-1104

35. Bonam SR, Wang F, Muller S (2019) Lysosomes as a therapeutic target. Nat Rev Drug Discov 18:923-948

36. Ballabio A, Bonifacino JS (2020) Lysosomes as dynamic regulators of cell and organismal homeostasis. Nat Rev Mol Cell Biol 21:101-118

37. Wang H, Zhou Y, Zhu Q, Zang H, Cai J, Wang J, Cui L, Meng X, Zhu G, Li J (2019) Staphylococcus aureus induces autophagy in bovine mammary epithelial cells and the formation of autophagosomes facilitates intracellular replication of Staph. aureus. J Dairy Sci 102:8264-8272

38. Ashley D, Hernandez J, Cao R, To K, Yegiazaryan A, Abrahem R, Nguyen T, Owens J, Lambros M, Subbian S, Venketaraman V (2020) Antimycobacterial effects of everolimus in a human granuloma model. J Clin Med 9:2043

\section{Publisher's Note}

Springer Nature remains neutral with regard to jurisdictional claims in published maps and institutional affiliations.

Ready to submit your research? Choose BMC and benefit from

- fast, convenient online submission

- thorough peer review by experienced researchers in your field

- rapid publication on acceptance

- support for research data, including large and complex data types

- gold Open Access which fosters wider collaboration and increased citations

- maximum visibility for your research: over 100M website views per year

At BMC, research is always in progress.

Learn more biomedcentral.com/submissions 